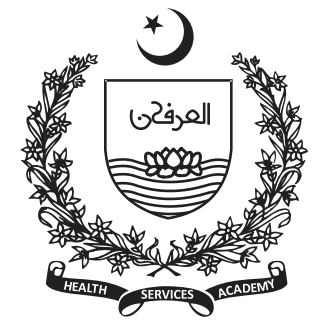

${ }^{1}$ Department of Nutrition, Rashid Latif Institute of Allied Health Sciences; Rashid Latif Medical Complex Lahore, Pakistan

Corresponding Author: Email: zoha1sohail@gmail.com

\section{Consumption of Milk and Milk Products Among Young People of Pakistan; Cross Sectional Study}

\author{
Zoha Sohail
}

\section{Abstract}

Background: Consumption of milk and milk products between 10-24 years of age is chief important; a crucial bone development age and during recent years consumption of milk and milk products had been decreased among young people. Current study was aimed to investigate the consumption of milk and milk products among young people of Pakistan.

Methods: Study design was Cross-sectional; two hundred individuals aged 10-24 years were selected via convenient sampling. Self-structured questionnaire with a combination of closed and open ended questions was used for data collection.

Results: Study provided that $152(76 \%)$ sample consumed milk once daily $298 \pm 234.90 \mathrm{ml}$ and $48(24 \%)$ did not consumed milk.

Conclusion: Results concluded that the consumption of milk and milk products among young people was low as compared to the recommended dietary allowances; thus a need to provide knowledge regarding the importance of milk consumption to assist in reducing bone health disorders

Keywords: Bone health, recommended dietary allowances, milk consumption, young people

\section{Introduction}

W

orld Health Organization (WHO) termed individuals aged 10-19 years as adolescents, individuals aged 15-24 years as youth and as these both age groups are overlapping so collectively they are termed as young people i.e.10-24 (1). This period of life span is a critical period for bone accretion; during this period individuals are expected to acquire peak bone mass (2). Peak bone mass is totally dependent on bone mineral percentage accreted during growing years, many modifiable and non-modifiable factors i.e. genetics, gender, hormonal status and lifestyle influence the achievement of peak bone mass (3). Risk of bone health disorders are dependent on bone mineral density and bone mineral content maintained and achieved during this crucial period (4). As adolescence is a transitional phase i.e. childhood to adulthood and is a complex mixture of rapid physical and mental growth; fulfilling the nutritional requirements during this phase of development is very important because imbalanced diet could end up not only with linear growth failure but also with altered psychomotor functions (5).

International Osteoporosis Foundation (IOF) in 2009 reported; in Pakistan out of 9.9 million subjects' 7.2 million women have osteoporosis. Moreover, it is expected that frequency of osteopenia is about 40 million in Pakistanis, and both genders are correspondingly suffering from this problem. It is also estimated that the prevalence of osteoporosis in Pakistan would increase to 11.3 million (2020) and 12.91 million (2050) (6). 
Bone growth stunted due to the deficiency of proteins, calcium, vitamin $\mathrm{D}$, vitamin $\mathrm{C}$, magnesium, zinc, manganese and copper. Half the volume of the extracellular material of bone consists of protein and the other half of calcium phosphate crystals; protein, calcium and phosphorous are required in bulk by bone cells. Among food groups, dairy products are very complex due to their nutrient composition and the effect of consumption of dairy products is more accounted as compared to the consumption of single nutrient. In concern to bone health, dairy products are inevitable due to presence of bone health mineral i.e. calcium (7)

Milk and milk products are the excellent source of calcium and the recommended dietary allowance of calcium for youth is $1300 \mathrm{mg} /$ day (8). Consume 3 servings of milk a day or $1300 \mathrm{mg}$ of calcium to maintain bone mineral density (9). One serving of milk contains $250 \mathrm{ml}$ milk, one serving of yogurt contains $3 / 4$ cup yogurt and one serving of cheese includes $1^{1 / 2}$ ounces of cheese. One cup whole milk contains $291 \mathrm{mg}$ calcium, one cup yogurt contains $415 \mathrm{mg}$ calcium, $1 / 2$ cup cottage cheese contains $77 \mathrm{mg}$ calcium (10).

Many factors contribute to the inhibition of milk's key nutrient absorption i.e. calcium in the body. Increased caffeine consumption i.e. $>500-600 \mathrm{mg} /$ day via tea (79cups) and coffee (4-7cups) hinder calcium's absorption in the body; though the recommendation for caffeine consumption is up to $400 \mathrm{mg} /$ day $^{-1}$ (11). Other than caffeine, sugar also imposes a detrimental effect on bone health and metabolism; consumption of 100grams sugar a day promotes to negative calcium balance (12).

A descriptive study was conducted on 205 young adults aged 19-24 years in Ankara with an objective to determine the consumption of milk and knowledge about milk among the selected sample; data was collected via questionnaires and face to face interview sessions. Results concluded that $42 \%$ consumed milk regularly and $58 \%$ had irregular milk consumption and the results of other objective showed that males had higher knowledge about milk than females i.e. $17.54 \pm 4.36$ and individuals aged 22-24 scored higher i.e. 18.14 \pm 4.34 than individuals aged between 19-21 about knowledge of milk (21).

A cross sectional study entitled "Social support and dairy products intake among adolescents: a study from Iran" was conducted on 402 high risk adolescents enrolled in $7^{\text {th }}$ grade with an objective to determine the consumption of milk and milk products as per recommended daily servings. Data was collected via self-structured questionnaire contained questions regarding perceived social support, physical activity and sedentary behaviors along with this a food frequency questionnaire (FFQ) for measuring milk consumption. Results of the current study concluded that average daily intake of milk and milk products was 1.64 servings per day and overall $14.2 \%$ adolescents consumed milk and its products as per the recommendations (22).

\section{Methodology}

\section{Study design and sampling:}

This was a quantitative, non-experimental, and crosssectional study conducted from (January 2020- April 2020). Sample size of this study was two hundred young adults aged 10-24 years collected via convenient sampling technique; before collection informed written consent was taken from the sample. The purpose of this study was to determine the consumption of milk and milk products among young people.

A self-structured questionnaire with a combination of closed and open ended questions was distributed among the samples of the study. Questions asked from the selected sample included the socio-demographic profile and frequency of consumption of milk and milk products via food frequency questionnaire (20). Income level was classified as lower class, middle class and upper strata (13).

Statistical Analysis:

Normality of data was determined using Shapiro Whilk test and statistical analysis was done by ANOVA followed by Tukey's Test. A p-value of $\leq 0.05$ was considered as statistically significant.

\section{Results}

Demographic profile i.e. age, gender, income status and educational levels of the samples stated in table 1.1 .

Table 1. Socio-Demographic characteristics

\begin{tabular}{|c|l|l|}
\hline Variable & Frequency & $\begin{array}{l}\text { Percentage } \\
\mathbf{( \% )}\end{array}$ \\
\hline Gender & & \\
\hline Male & 114 & 57.0 \\
\hline Female & 86 & 43.0 \\
\hline Age (Years) & & \\
\hline $10-14$ & 20 & 10 \\
\hline
\end{tabular}


Consumption of Milk and Milk Products Among Young People of Pakistan; Cross Sectional Study

\begin{tabular}{|l|l|l|}
\hline \multicolumn{1}{|c|}{$15-19$} & 65 & 42.5 \\
\hline \multicolumn{1}{|c|}{$20-24$} & 115 & 57.5 \\
\hline Income Status & & \\
\hline Lower class & 0 & 0 \\
\hline Lower Middle class & 45 & 22.5 \\
\hline Upper Middle class & 75 & 37.5 \\
\hline Middle class & 51 & 25.5 \\
\hline Upper class & 29 & 14.5 \\
\hline Education Level & & \\
\hline Undergraduate & 127 & 63.5 \\
\hline Graduate & 73 & 36.5 \\
\hline
\end{tabular}

Table 2. General frequency of consumption of different types of milk

\begin{tabular}{|l|l|l|l|}
\hline \multicolumn{1}{|c|}{ Types of milk } & $\begin{array}{l}\text { Frequency } \\
\text { (n) }\end{array}$ & $\begin{array}{l}\text { Percentage } \\
(\%)\end{array}$ & P. value \\
\hline Fresh Milk & & & \\
\hline Buffalo milk (Whole) & 12 & 6.0 & \\
\hline Buffalo milk (Skimmed) & 19 & 9.5 & \\
\hline Goat milk (Whole) & 0 & 0 & \\
\hline Goat milk (Skimmed) & 0 & 0 & \\
\hline Camel milk (Whole) & 0 & 0 & \\
\hline Camel (Skimmed) & 0 & 0 & \\
\hline $\begin{array}{l}\text { Ultra Heat Treated } \\
\text { (UHT) }\end{array}$ & & & \\
\hline Good Milk & 0 & 0 & \\
\hline Milk Pak & 49 & 24.5 & $<0.001$ \\
\hline Olpers & 41 & 20.5 & \\
\hline Nurpur & 0 & 0 & \\
\hline Dayfresh & 0 & 0 & \\
\hline Pasteurized milk & & & \\
\hline Anhaar & 9 & 4.5 & \\
\hline Prema & 10 & 5 & \\
\hline Malmo & 0 & 0 & \\
\hline Gourmet & 0 & 0 & \\
\hline Adams & 0 & 0 & \\
\hline Powdered milk & & & \\
\hline Nido & 11 & 5.5 & \\
\hline Types of Milk products & & & \\
\hline Yogurt & & & \\
\hline Homemade yogurt & 46 & 5.5 & \\
\hline Packaged yogurt & 17 & & \\
\hline Cheese & & & \\
\hline Cottage cheese & & & \\
\hline Mozerrela cheese & & \\
\hline Cheddar cheese & & \\
\hline Milkshake & & & \\
\hline Fresh fruit milkshake & & \\
\hline
\end{tabular}

\begin{tabular}{|l|l|l|l|}
\hline Tea & & & \\
\hline Fresh milk tea & 81 & 40.5 & \\
\hline Packaged milk tea & 30 & 15 & \\
\hline Tea Whitener Tea & & & $<0.05$ \\
\hline Everyday & 87 & 43.5 & \\
\hline Tarang & 2 & 1 & \\
\hline Cupshup & 0 & & \\
\hline Qudrat & 0 & & \\
\hline Tea Max & 0 & & \\
\hline Milk based desserts & 34 & 17 & \\
\hline Addition of sugar & & & \\
\hline Yes & 166 & 83 & $<0.05$ \\
\hline No & 34 & 17 & \\
\hline
\end{tabular}

${ }^{*}$ p-value significant at $<0.05$

Consumption of ultra-heat treated milk was statistically higher than other types of milk; study provided that $90(45 \%)$ consumed ultra-heat treated milk (UHT) then followed by fresh milk i.e. 31(15.5\%) then followed by pasteurized milk i.e. 19(9.5\%), then followed by powdered milk i.e. 11(5.5\%). Data analysis revealed that consumption of tea made of tea whitener was $1600.86 \pm 257.30 \mathrm{ml}$ that was high as compared to the recommendations. It was also found that $166(83 \%)$ sample added sugar in milk and milk products and quantity of sugar added in milk and milk products by selected sample was $110 \pm 20 \mathrm{~g} /$ day that was in elevation as compared to the recommendations; $p$ value was statistically significant $(\mathrm{p}=<0.05)$.

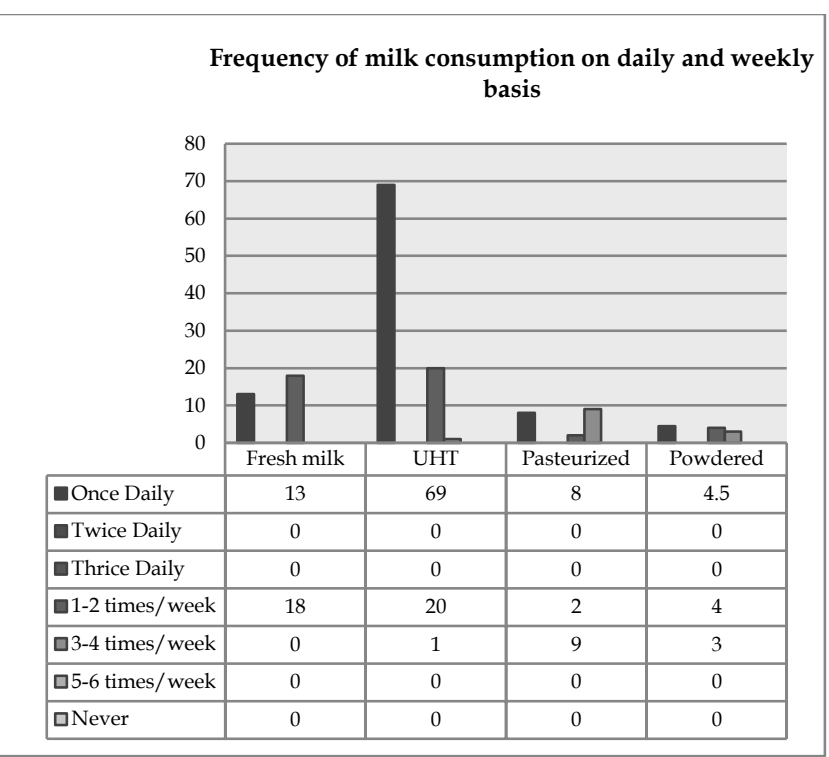

Figure 1. Frequency of milk consumption on daily weekly and weekly basis 


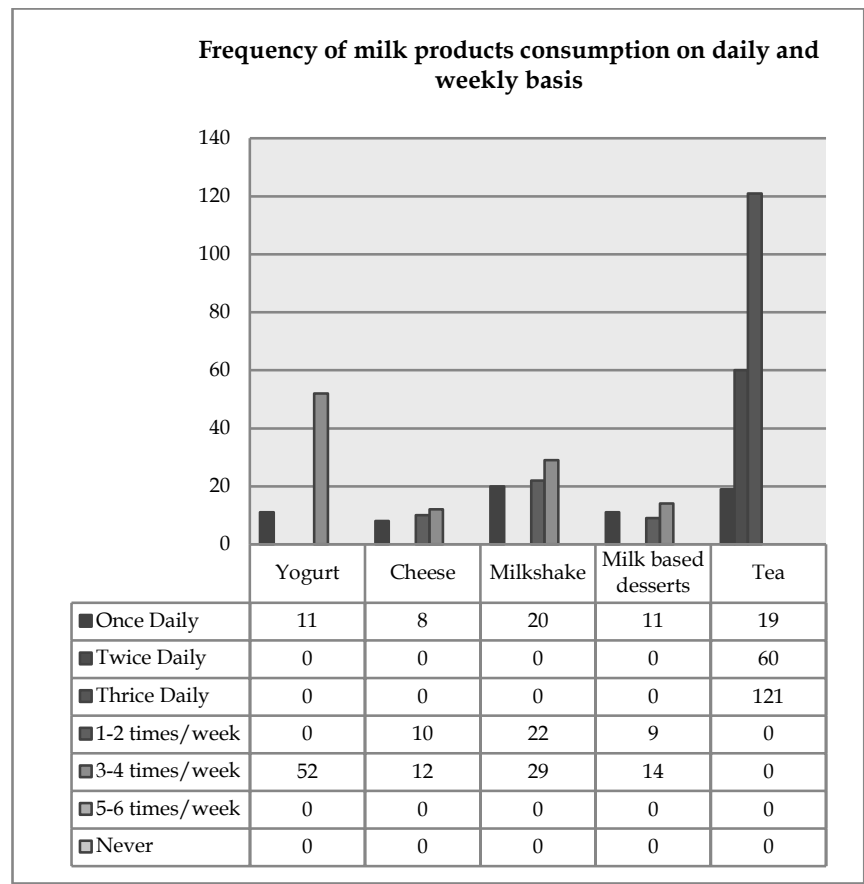

Figure 2. Frequency of milk products consumption daily, weekly and monthly

Above mentioned figure shows that consumption of ultra-heat-treated milk on daily basis was higher i.e. $69(34.5 \%)$ as compared to other types of milk.

Table 3. Serving size of milk and milk products consumed daily

\begin{tabular}{|l|l|}
\hline \multicolumn{1}{|c|}{ Types of products } & \multicolumn{1}{c|}{$\begin{array}{c}\text { Serving size/Daily } \\
\text { M } \pm \text { SD }\end{array}$} \\
\hline Milk & $298 \pm 234.90 \mathrm{ml}$ \\
\hline Cheese & $3.80 \pm 1.24 \mathrm{oz}$ \\
\hline Yogurt & $3.37 \pm 1.91 \mathrm{oz}$ \\
\hline Milkshakes & $200 \pm 100 \mathrm{ml}$ \\
\hline Milk based desserts & $6.8 \pm 3.4 \mathrm{oz}$ \\
\hline Tea & $1600.86 \pm 257.30 \mathrm{ml}$ \\
\hline Addition of sugar & $110 \pm 20 \mathrm{~g}$ \\
\hline
\end{tabular}

*Consumption of milk and milk products among study sample was low as compared to recommendations; difference was statistically significant $(\mathrm{p}=<0.05)$ and obtained using Tukey's test.

\section{Discussion}

Results of the current study indicated that consumption of milk among young people was low as compared to the recommendations i.e. $298 \pm 234.90 \mathrm{ml}$ (Heaney, 2009) states that three or four glasses of milk should be consumed daily whereas results of the current study are not in accordance to the recommendations (7). One cup whole milk contains $291 \mathrm{mg}$ calcium and recommended dietary allowance of calcium for youth is $1300 \mathrm{mg}$ / day (10). In Pakistan's population decreased calcium intake is one of the most prominent influencer for causing osteoporosis; study concluded that $30.7 \%$ individuals were suffering from osteoporosis and 44.5\% were suffering from osteopenia (14). A similarly study was conducted in Karachi to determine the nutritional status, dietary practices and physical activities of adolescents in public and private schools and concluded that $50 \%$ of the adolescent boys and girls were at the risk of calcium deficiency (5). A study was conducted in which they examined data from repeated cross sections of the National Health and Nutrition Examination Survey (NHANES), 1999 to 2016 and targeted population was individuals aged 2-20years. According to survey $32.4 \%$ consumed whole milk, $41.8 \%$ consumed milk with $4 \%$ fat, $11.8 \%$ consumed milk with $1 \%$ fat and $10.3 \%$ consumed fat free milk. Results of the current study are not in accordance with the above discussed study i.e. individuals consumed more fresh skimmed milk i.e. 19(9.5\%)as compared to fresh whole milk 12(6.0\%) (15). American heart association recommends low-fat or reduced-fat ranges in place of whole $(4 \%)$ milk for those aged 2 years and older (16).

A study investigated consumer behavior in yogurt purchase and consumption. Study only enrolled subjects who purchased yogurt from the particular outlet i.e. PARC Agrotech Company Limited (PATCO) shop in the National Agriculture Research Center (NARC) only twenty seven individuals fill up their developed questionnaire. Results of the study concluded that 9(33.33\%) individuals consumed yogurt daily, 1(3.70\%) consumed yogurt 1-2 times/week and 7(25.93\%) consumed yogurt 3-6 times/week. Results of the current study are in accordance with the above study i.e. 13(20.6\%) consumed yogurt daily, $31(49 \%)$ consumed yogurt twice a week and $19(30 \%)$ consumed yogurt thrice a month and daily yogurt consumption in selected sample was $3.37 \pm 1.91 \mathrm{oz}$. In both studies, consumption of yogurt was not as per the recommendations (17). However, literature states that consume three servings of milk or milk products daily (9) and one serving of yogurt is $3 / 4$ cup (10)

The results of present study concluded that $100 \%$ of the selected sample consumed tea daily. A study 
reported that consumption of caffeine containing food items influences a negative impact on the absorption of calcium in the body in such a way caffeine lowers the kidney reabsorption of calcium and other than the renal reabsorption caffeine also decreases the efficiency of intestinal calcium absorption. Other than these two factors caffeine consumption also lowers the levels of inositol in the blood that also plays a role in the metabolism of calcium which then eventually leads to the excretion and mal-absorption of calcium (18). Effect of caffeine consumption on calcium balance and bone health is dependent on the quantity of both variables i.e. caffeine and calcium. Author concluded that consuming $800 \mathrm{mg}$ of calcium a day and along with $400 \mathrm{mg}$ of caffeine a day does not have any generous effect on the health of bones (11). Whereas results of this current study concluded that daily tea consumption among young people was $1600.86 \pm 257.30 \mathrm{ml}$.

Other than caffeine consumption, consumption of white sugar also have a very negative substantial influence on the bone health and calcium status; excessive sugar consumption eventually takes to osteoporosis in such a way it increases urinary calcium excretion, it decreases calcium absorption, it hinders calcium transportation to intestines, it obstructs vitamin $\mathrm{D}$ activation, it increases osteoclastic activation and decreases osteoblastic activation. Consumption of 100 grams of sugar a day contributes to increased urinary evacuation of minerals i.e. calcium, magnesium and potassium (12). Results of this study concluded that daily sugar consumption among young people was $110 \pm 20 \mathrm{~g}$.

$127(63.5 \%)$ were undergraduates and $73(36.5 \%)$ were graduated; as $100 \%$ of the current study sample was educated. Literature states that; to improve the consumption of milk and milk products one approach that could be very helpful in refining the intake micronutrients is improving the public's knowledge about nutrients and health because mal-concepts and mal-beliefs negatively effects food consumption (19).

\section{Conclusion}

Results concluded that the consumption of milk and milk products was low among young people as compared to the recommendations. Thus current study highlighted the need to facilitate measures that must be followed to increase awareness regarding importance of milk consumption as per recommendations and the consequences of not consuming milk for young people; a bone modeling age. Along with this regular bone mineral density must also be screened for early detection and eradication of any bone health disorder.

\section{Recommendation}

Future studies must be conducted:

- To assess the frequency of consumption of milk and milk products in other age groups i.e. infants, toddlers, pre-scholars, school going and adults and among pregnant and lactating females.

- To determine the reasons that leads to decreased consumption of milk and milk products among different age groups.

- To determine the effect of plant based calcium sources on bone health of individuals with Limitations lactose intolerance or vegetarianism.

Bone mineral density of the selected sample was not measured due to lack of funds though it should be measured to assess the relationship between bone mineral density and consumption of milk and milk products.

\section{References}

1. Sunitha S, Gururaj G. Health behaviours \& problems among young people in India: Cause for concern \& call for action. The Indian journal of medical research. 2014 Aug;140(2):185.

2. Gordon RJ, Gordon CM. Adolescents and Bone Health. Clinical Obstetrics and Gynecology. 2020 Sep 1;63(3):504-11.

3. Zhu K, Prince RL. Calcium and bone. Clinical biochemistry. 2012 Aug 1;45(12):936-42.

4. Ondrak KS, Morgan DW. Physical activity, calcium intake and bone health in children and adolescents. Sports medicine. 2007 Jul;37(7):587-600.

5. Paracha PI, Bakht S, Paracha SI, Vriesekoop F, Alam I, Din Z, Ullah N. Nutritional status, dietary practices and physical activities of adolescents in public and private schools of Karachi, Pakistan. Obesity Research-Open Journal. 2016 Aug 3;3(2):30-9.

6. Mithal A, Dhingra V, Lau E. The asian audit: Epidemiology, costs and burden of osteoporosis in Asia. Beizing, China: An International Osteoporosis Foundation (IOF) publication. 2009.

7. Heaney RP. Calcium, dairy products and osteoporosis. Journal of the American college of nutrition. 2000 Apr 1;19(sup2):83S-99S.

8. Caroli A, Poli A, Ricotta D, Banfi G, Cocchi D. Invited review: dairy intake and bone health: a viewpoint from 
the state of the art. Journal of dairy science. 2011 Nov 1;94(11):5249-62.

9. Kalkwarf HJ, Khoury JC, Lanphear BP. Milk intake during childhood and adolescence, adult bone density, and osteoporotic fractures in US women. The American journal of clinical nutrition. 2003 Jan 1;77(1):257-65.

10. Rolfes, S. R., Pinna, K., \& Whitney, E. (2020). Understanding normal and clinical nutrition. Cengage learning.

11. Nawrot P, Jordan S, Eastwood J, Rotstein J, Hugenholtz A, Feeley M. Effects of caffeine on human health. Food Additives \& Contaminants. 2003 Jan 1;20(1):1-30.

12. DiNicolantonio JJ, Mehta V, Zaman SB, O'Keefe JH. Not salt but sugar as aetiological in osteoporosis: A review. Missouri medicine. 2018 May;115(3):247.

13. Subohi A. Defining income groups. published in Daily Dawn dated. 2006:20-11.

14. Haris S, Jahan F, Afreen A, Ahmed H, Ahmed Z. To determine the risk factors and prevalence of osteoporosis among adult Pakistani population residing in Karachi using quantitative ultrasound technique. J Community Med Health Educ. 2014;4(4):2-5.

15. White MJ, Armstrong SC, Kay MC, Perrin EM, Skinner A. Associations between milk fat content and obesity, 1999 to 2016. Pediatric obesity. 2020 May;15(5):e12612.

16. McGuire S. US department of agriculture and US department of health and human services, dietary guidelines for Americans, 2010. Washington, DC: US government printing office, January 2011. Advances in nutrition. 2011 May;2(3):293-4.
17. Raza I, Masood MA, Shaukat MH, Hassan M, Abid S,\& Usman T. Consumer behavior in yogurt purchase and consumption. Global journal of Science Frontier Research: Agricuture and Veterinary. 2020. 20(5): 8

18. Al-Othman A, Al-Musharaf S, Al-Daghri NM, Yakout S, Alkharfy KM, Al-Saleh Y, Al-Attas OS, Alokail MS, Moharram O, Sabico S, Kumar S. Tea and coffee consumption in relation to vitamin $\mathrm{D}$ and calcium levels in Saudi adolescents. Nutrition journal. 2012 Dec;11(1):1-6.

19. Allen S, Goddard E, Farmer A. How knowledge, attitudes, and beliefs impact dairy anti-consumption. British Food Journal. 2018 Oct 1.

20. Szymelfejnik EJ, Wadolowska L, Cichon R, Przyslawski J, Boleslawska I. Dairy products frequency questionnaire (ADOS-Ca) calibration for calcium intake evaluation. Polish journal of food and nutrition sciences. 2006 Jan 1;15(1):229.

21. Ozdogan Y, Yardimci H, Ozcelik AO. Young adults' milk consumption habits and knowledge about milk. Studies on Ethno-Medicine. 2017 Jan 2;11(1):106-13. Ozdogan Y, Yardimci H, Ozcelik AO. Young adults' milk consumption habits and knowledge about milk. Studies on Ethno-Medicine. 2017 Jan 2;11(1):106-13.

22. Shokrvash B, Salehi L, Akbari MH, Mamagani ME, Nedjat S, Asghari M, Majlessi F, Montazeri A. Social support and dairy products intake among adolescents: a study from Iran. BMC public health. 2015 Dec;15(1):1-0. 